\title{
COVID-19-Akut Pankreatit İlişkisinin İncelenmesi
}

\author{
Emine Kübra DİNDAR DEMİRAY*, Mustafa YILMAZ ${ }^{* *}$, \\ Işıl Deniz ALIRAVCI ${ }^{* * *}$, Sevil ALKAN ÇEVIKKER ${ }^{* * * *}$
}

\section{$\ddot{O} \mathbf{z}$}

Koronavirüs hastalığı-19 (COVID-19) pandemisi şu an için dünya çapında iki milyondan fazla insanın ölümüne neden olmuştur. Hastalı̆̆ın ciddiyeti subklinik infeksiyonlardan hastaneye yatmayı gerektiren ağır hastalığa kadar değişmektedir. COVID-19 hastalık etkeni olan SARS-CoV2 esas olarak solunum yolunu etkiler, ancak mide bulantısı, kusma ve ishal gibi gastrointestinal semptomlar da ortaya çıkabilmektedir. Karın ağrısı, COVID-19 hastalığı ile ilişkili bilinen semptomlardan biridir. Şiddetli COVID-19 infeksiyonunun bir komplikasyonu olarak akut pankreatit gelişimi hakkında çok az veri bulunmaktadır. COVID-19 hastalarının bazılarında pankreas enzim yüksekliği ve nadir de olsa akut pankreatit gelişebilmektedir. Bu durum özellikle ciddi klinik tablo ile ilişkilidir. COVID-19'da pankreas tutulum mekanizması net anlaşılamamıştır. Bu derlemede COVID-19 ilişkili pankreatitin değerlendirilmesi amaçlanmıştır.

Anahtar Kelimeler: COVID-19, akut pankreatit, SARS-CoV-2.

\footnotetext{
Derleme Makale (Review Article)

Geliş / Received: 24.10.2020 \& Kabul / Accepted: 11.03.2021

DOI: https://doi.org/10.38079/igusabder.815768

${ }^{*}$ Uzm. Dr,. Bitlis Devlet Hastanesi, Enfeksiyon Hastalıkları ve Klinik Mikrobiyoloji Bölümü, Bitlis, Türkiye, E-posta: e.kubradindar@hotmail.com ORCID https://orcid.org/o00o-0001$\underline{6459-7182}$

** Uzm. Dr., Kütahya Sağlık Bilimleri Üniversitesi, Evliya Çelebi Ĕgitim ve Araştırma Hastanesi, Enfeksiyon Hastalıkları ve Klinik Mikrobiyoloji Bölümü, Kütahya, Türkiye, E-posta: drmustafayilmaz29@hotmail.com ORCID https://orcid.org/oooo-0001-6874-0619 *** Uzm. Dr., Manavgat Devlet Hastanesi, Enfeksiyon Hastalıkları ve Klinik Mikrobiyoloji Bölümü, Antalya, Türkiye, E-posta: dr_isildeniz@hotmail.com ORCID https://orcid.org/oooo0002-4740-1579

${ }^{* * * *}$ Dr. Öğr. Üyesi, Çanakkale Onsekiz Mart Üniversitesi, Tıp Fakültesi, Enfeksiyon Hastalıkları ve Klinik Mikrobiyoloji Anabilim Dalı, Çanakkale, Türkiye, E-posta: $\underline{\text { s-ewil@hotmail.com }}$ ORCID https://orcid.org/o000-0003-1944-2477
} 


\title{
Investigation of Relationship with COVID-19 and Acute Pancreatitis
}

\begin{abstract}
More than 2 million people worldwide have died due to coronavirus disease-19 (COVID-19). The severity of the disease ranges from subclinical infections to severe illnesses requiring hospitalization. SARS-CoV-2, which is the causative agent of COVID-19 disease, mainly affects the respiratory tract, but gastrointestinal symptoms such as nausea, vomiting and diarrhea may also occur. Abdominal pain is one of the known symptoms associated with COVID-19 disease. There are a few data on the development of acute pancreatitis as a complication of severe COVID19 infection. Some patients with COVID-19 may develop an elevated pancreatic enzyme and rarely acute pancreatitis. This situation is associated with a particularly serious clinical picture. The mechanism of pancreatic involvement in COVID-19 is not clearly understood. In this review, it was aimed to evaluate COVID-19 associated pancreatitis.
\end{abstract}

Keywords: COVID-19, acute pancreatitis, SARS-CoV-2.

\section{Giriş}

Akut pankreatit (AP) pankreasın inflamatuar bir hastalı̆̆ olup hafif ödematöz pankreatitten, yüksek mortalite riski oluşturan şiddetli nekrotizan pankreatite kadar uzanan yelpazede heterojen bir hastalıktır ${ }^{1}$. Yetişkinlerde gelişen akut pankreatitin birçok nedeni vardır. Özellikle safra kesesi taşlarının pasajı veya sıkışması en sık pankreatit sebepleri arasında sayllabilir. Diğer pankreatit sebepleri ise; alkol kullanımı, viral enfeksiyonlar, bazı metabolik bozukluklar, bir otoimmün hastalıklar, ilaçlar ve maruz kalınan toksinler olarak düşünülebilir².

Virüs kaynaklı pankreatit literatürde iyi tanımlanmış olup, en yaygın olarak Kabakulak, Kızamık, Coxsackie, Epstein-Barr Virüsü ve Hepatit-A virüsünden kaynaklı viral pankreatit vakaları bildirilmiştir ${ }^{3}$. Yakın zaman da $\mathrm{H} 1 \mathrm{~N} 1$ influenza ile akut pankreatit arasında ilişki olduğunu düşündüren az sayıda vaka bildirilmiştir4,5.

Koronavirüs hastalı̆̆1-19 (COVID-19) pandemisi şu an için dünya çapında iki milyondan fazla insanın ölümüne neden olmuştur ${ }^{6}$. Hastalığın ciddiyeti subklinik enfeksiyonlardan hastaneye yatmayı gerektiren ağır hastalığa kadar değişmektedir. COVID-19 hastalık etkeni olan şiddetli akut solunum yolu sendromu koronavirüsü 2 (SARS-CoV-2) esas olarak solunum yolunu etkiler7. Ancak karın ağrısı, bulantı, kusma ve ishal gibi 
gastrointestinal semptomlar da ortaya çlkabilmektedir. SARS-CoV-2 RNA'sı Amerika Birleşik Devletleri'nde (ABD) ilk olarak mide bulantısı, kusma ve ishal belirtileri olan COVID-19 vakasının dışkısında tespit edildiğinden sindirim sistemi ilgili araştırmalar artmaktadır ${ }^{8}$.

SARS-CoV reseptörü olan Anjiyotensin dönüştürücü enzim 2 (ACE 2), pankreas adacıklarında yüksek oranda saptanmış, gelişen enfeksiyonun, adacık hasarına ve ardından akut diyabete sebep olduğu bildirilmiştir`. Yine Çin'de yayınlanan 52 COVID19 hastasından oluşan bir vaka serisinde, COVID-19 enfeksiyonunun pankreas üzerinde doğrudan bir etkisi olduğunu öne sürülmüş ve aktif COVID-19 vakalarının \% 17'sinde pankreas hasarı ve tanımlanmış lipaz yüksekliği olduğunu bildirmiştirio.

McNabb-Baltar ve ark. ${ }^{11}$ ise Amerika Birleşik Devletlerinde (ABD) PCR ile konfirme 71 COVID-19 hastasında lipaz yüksekliğini ve pankreattit varlığını araştırmış olup; hastaların 9'unda (\%12,1) hiperlipazemi ve ikisinde $(\% 2,8)$ normalden 3 kat fazla lipaz değeri saptamıştır. Ancak hiçbir hastada akut pankreatit gelişmemiş olup, hiperlipazemi kötü prognoz ile ilişkili bulunmamıştır.

Şiddetli COVID-19 enfeksiyonunun bir komplikasyonu olarak akut pankreatit gelişimi hakkında çok az veri bulunmaktadır³. Bu derlemede, mevcut literatür kanıtları rehberliğinde sindirim sistemi organlarından olan pankreasın COVID-19 enfeksiyonu seyri sırasında etkilenmesi irdelenmiştir.

\section{COVID-19 Pankreas Tutulumu: Olası Mekanizma ve Tanı}

COVID-19'daki pankreas organ hasarının doğrudan viral tutulumdan ya da ciddi seyreden klinik durumlarda önemli bir pankreas hasarı olmaksızın enzim anormalliklerinden kaynaklanabildiği ifade edilmektedir. Bugüne kadar yapılan çalışmalar ile SARS-CoV-2'nin akut pankreatite yol açan pankreas hücre hasarına neden olup olamayacağını kesin olarak tespit edilememiştiri². Güncel konsensus akut pankreatit tanısı için: pankreatitle uyumlu karın ağrısı, serum amilaz / lipazın normal üst sınırı 3 katından fazla olması ve görüntülemede karakteristik bulguların olması kriterlerinden üçünden ikisi varsa akut pankreatit tanısı konulacağı yönündedir ${ }^{13}$.

COVID-19 gelişen hastalarda pankreatit gelişimine sebep olduğu düşünülen farklı görüşler mevcuttur. 
a) Doğrudan viral tutulum: Doğrudan yerel SARS-CoV-2 replikasyonunun aracılık ettiği sitopatik etkiyle veya dolaylı sistemik yanıttan kaynaklanan pankreas hasarı veya solunum yetmezliği veya SARS-CoV-2 enfeksiyonunun neden olduğu zararlı bağışıklık tepkisi sonucu orta derece klinik tablolu pankreatit saptanmıştır ${ }^{10}$.

b) Klinik parametrelere göre enzimatik artış -psödopankreatit, pankreatit benzeri klinik sendrom: $\mathrm{Bu}$ tabloda özellikle sekonder enzim artışları izlenebilmektedir ${ }^{10}$.

c) Tedavide kullanılan ilaçlara sekonder gelişen pankreatit-ilaçla ilişkili pankreatit: $\mathrm{Bu}$ klinik tabloda pankreas hasarına klinik olarak karşımıza çlkabilmektedir. Antipiretikler özellikle suçlu bulunan ajanlardan biridir ${ }^{10}$.

Yine tedavide kullanılan Lopinavir/ritonavir p450 enzim sisteminin substratları olduğundan pek çok ilaç-ilaç etkileşimine neden olabilirler. Hastanın kullandığı ilaç kombinasyonu veya ilacın salt etkisi ile hepatit veya pankreatit gelişebilir ${ }^{14-16}$.

COVID-19 tedavisinde kullanılan metilprednisolon, deksametazon nadir de olsa pankreatite sebep olabilmektedir ${ }^{14-16}$.

Akut pankreatit teşhisi için altın standart yoktur, bu hayatı tehdit eden durumun teşhisini daha da zorlaştırır. Amilaz ve lipaz ölçümleri, AP teşhisinde kullanılan birincil yöntemlerdir; ancak bu enzimlerin özgüllük ve duyarlılık seviyeleri düşüktür. Tanı genellikle klinik parametrelerle konulabilir; ancak görüntüleme, klinik tablo net olmadığında tanıya yardımcı olmada önemli bir rol oynar. Ayrıca görüntüleme ile olası diğer nedenleri, komplikasyonları tespit etmeye ve görüntüleme puanlama sistemlerine dayalı olarak hastalık şiddetini değerlendirilebilir ${ }^{17-19}$. Kontrastlı bilgisayarlı tomografi, akut pankreatit tanısı için\% 9o'ın üzerinde duyarlılık ve özgüllük sağlar 17-19.

Karaciğer hastalığı olan hastalar arasında COVID-19 prevalansı araştırılmış olup, çalışmalar ciddi karaciğer hastalığının COVID-19 için orta derecede bir risk faktörü olduğunu göstermektedir ${ }^{20,21}$. COVID-19'un klinik özelliklerinin bir bütün olarak hepatopankreato-biliyer (HPB) grubu için araştırılması önemlidir, çünkü bu hastalıklar benzer klinik-biyolojik davranışlar sergilerler.

Hastalığın pankreas belirtileri nadir olmakla birlikte, pankreas veya safra rahatsızlıkları olan hastalarda COVID-19 prevalansına ilişkin çok sınırlı veri mevcuttur ${ }^{11,15}$. Ullah ve 
ark. ${ }^{22}$ önceden pankreas ve karaciğer rahatsızlı̆̆ı olan hastalarda COVID-19 riskinin daha yüksek olduğunu ve azalmış pankreas fonksiyonunun, sindirimin değişmesine ve dolayısıyla bağırsak florasının bozulmasına yol açarak, hastaları enterik yol ile patojenlere daha duyarlı hale getirebileceğini bildirmiştir.

Bazı COVID-19 hastalarında gastrointestinal tutulum tek organa lokalize olmadığına dair literatür bilgisi mevcuttur. Del Hoyo ve ark. ${ }^{23}$ yaygın splanknik ven trombozu, hem hepatobilier hem de pankreatik tutulum olan 61 yaşında ölümcül seyreden bir COVID19'lu vaka bildirmiştir.

Hem karaciğer hem de pankreas tutulumu, COVID-19 hastalığının şiddeti ile ilişkilidir. Şiddetli COVID-19 hastalığı olan hastalarda serum amilaz ve lipaz seviyeleri yükselebilir24. SARS-CoV-2 enfeksiyonu sırasında pankreas hasarı, artmış serum amilaz ve lipaz seviyeleri olarak tanımlanır, akut pankreatit öyküsü olan hastalarda COVID-19 prevalansı daha yüksek olabilir ${ }^{25}$. Barlass ve ark. ${ }^{26}$ çalışmalarında 1.003 COVID-19'lu hastanın 83'ünde lipaz seviyeleri artma olduğunu ve bunun daha kötü hastalık sonuçlarıyla ilişkili olduğunu bildirmiştir. Çalışmada, 83 kişiden 14'ünde $(\%$ 16,8) yüksek lökositoz oranları $(\mathrm{p}<\mathrm{0,001)}$ ve anormal karaciğer enzimleri $(\mathrm{p}<0,01)$ ile ilişkili olan yüksek lipaz $(>3 \times \mathrm{ULN})$ vardı. Daha düşük lipaz seviyeleri $(<3 \times \mathrm{ULN})$ ile karşılaştırıldığında, lipaz yüksekliği olan hastalarda daha yüksek yoğun bakım ünitesi (YBÜ) yatış oranları (\% 92,9'a karşı \% 32,8; p<0,001) ve entübasyon (\% 78,6'ya karşı \% 23,5; $\mathrm{p}=0,002$ ) vardı. Çok değişkenli analizde, daha yüksek lipaz seviyeleri YBÜ kabul ve entübasyon oranı ile önemli ölçüde ilişkiliydi.

Wuhan'da Wang ve ark..$^{10}$ tarafından yapılan çalışmada, 52 COVID-19 pnömonisi ile takip edilen hastanın \%17'sinde pankreatik hasar tespit edilmiştir. 52 hastanın içerisinde pankreas hasarı çıkan 9 hastanın sadece 6'sında kanda glukoz oranı yüksek olup, bu çalışmada, pankreas hasarı insidansının çok düşük olmadığını saptanmıştır. $\mathrm{Bu}$ çalışmada; pankreas hasarı olan hastaların, kabul sırasında iştahsızlık, ishal ve ağır hastalığa sahip olma olasılığı daha yüksekti. Pankreas hasarı olmayan hastalar, pankreas hasarı olan hastalarla karşılaştırıldığında daha yüksek iştahsızlık ve ishal insidansı olduğu, başvuru sırasında daha ağır hastalık tablosunda olduğu saptanmıştır. Ayrıca laboratuvar tetkiklerine bakıldığında; daha düşük düzeyde $\mathrm{CD}_{3}$ + T ve $\mathrm{CD} 4$ + T hücresi, daha yüksek düzeyde Aspartat Aminotransferaz (AST), Gamma glutamil transferaz 
(GGT), kreatinin, Laktat dehidrogenaz (LDH) ve Eritrosit sedimentasyon hızı (ESH) değerleri olduğu bildirilmiştir ${ }^{10}$.

2003 yılında SARS-COV-1 virüsünün de yalnızca akciğer, karaciğer, böbrek ve bağırsak dokularında değil, aynı zamanda pankreası da hedef aldığı saptanmıştır ${ }^{20}$. Dahası, SARS$\mathrm{CoV}$ reseptörü ACE2, pankreas adacıklarında SARS-CoV 2 hastalığında yüksek oranda saptanmıştır. Gelişen enfeksiyon, pankreas adacıklarda hasara ve ardından akut diyabete sebep olmuştur ${ }^{27}$. Singla ve ark. ${ }^{24}$ da benzer şekilde; COVID-19 enfeksiyonuna pankreas adacık hücrelerinin katılımının, kan şekeri seviyelerinin bozulmasına yol açabileceği ve potansiyel olarak ilerleyen zamanlarda diabetes mellitusa yatkınlık yaratabileceğini savunmuştur.

Yine Hussain ve ark. ${ }^{28}$ yaptı̆̆ı çalışmada SARS-CoV-2'nin kronik inflamasyonu artırması ve pankreatik hasara neden olması diyabet ve COVID-19 arasındaki ilişkiyi ortaya koyduğunu, pankreas hasarına sebep olan bu kaskadın pankreatik enzim yüksekliği olarak kliniğe yansıdı̆̆ını bildirmiştir.

Yayınlanmış literatürde; koronavirüsün gelincik ve güvercinlerde AP'ye neden olan raporları olmasına rağmen, SARS-CoV-2'nin neden olduğu tamamen bilimsel olarak kanıtlara dayanan insanda rapor edilmiş AP vakası yoktur²9,30.

Aloysius ve ark. ${ }^{31} 36$ yaşında obez (Beden Kütle İndeksi=35kg/m²), modifiye Atlanta kriterlerine göre ciddi AP tanısı alan İspanyol bir kadın hastanın nazal sürüntüsünde ters transkriptaz-polimeraz zincir reaksiyonu (RT-PCR) ile SARS-CoV-2 tespit ettiklerini bildirmişlerdir. Bu hastada yüksek akışlı oksijen takviyesi gerektiren akut hipoksik solunum yetmezliği gelişmiş, iki haftalık destek tedavi ile gastrointestinal ve pulmoner semptomlarının kademeli olarak düzelmiştir.

Cheung ve ark. ${ }^{2}$ ise COVID-19 ile ilişkili tekrarlayan ilk olası akut pankreatiti olan 38 yaş bir erkek hastayı bildirmiştir. Lakshmanan ve ark.33 hafif COVID-19 enfeksiyonu olan sadece gastrointestinal semptomlarla başvuran bir akut pankreatit vakasını bildirmiştir. Nikhil Kumar Patnaik ve ark.34 da benzer şekilde, AP ile başvuran COVID-19 enfeksiyonlu bir hastayı bildirmiştir. Bu hastanın pankreatit tanısı, laboratuar ve radyolojik kanıtlara dayandırılmış ve tüm olağan etiyolojiler dışlanmıştır. Yazarlar, bu vakada, COVID-19 ile pandemisinde görülen bu vakanın, yeni koronavirüsün neden olduğu pankreas hasarını kuvvetle düşündürdüğünü savunmuştur. Meireles ve ark.35 
COVID-19 hastasında akalküloz AP varlığını bildirmiştir. Miao ve ark. ${ }^{36}$ ve Mukherjee ve ark.37 da COVID-19'un benzer şekilde pankreası etkileyebileceğini bildirmiştir.

İngiltere'den Szatmary ve ark. ${ }^{38}$ de kanıtlanmış 5 akut pankreatit vakasını bildirmiştir. $\mathrm{Bu}$ hastaların tamamı genç yaşta (ort. yaş:42) ve obez erkeklerdi. Hepsinde farklı düzeylerde hepatik steatoz mevcuttu.

Gubatan ve ark. ${ }^{25}$ ise akut pankreatit öyküsü olan hastaların COVID-19'a daha duyarlı olabileceğini bildirmiştir, ancak bu fenomenin mekanizması bilinmemektedir.

Liu ve ark. ${ }^{12}$ çalışmalarında, 121 COVID-19 hastasını değerlendirmiş, hafif seyirli hastaların \%1,85’inde hem amilaz hem de lipaz yüksekliği, ağır klinik seyirli hastaların ise \%17,91'sinde amilaz, \%16,41'inde ise lipaz yüksekliği olduğunu saptamıştır. Şiddetli COVID-19'u olan 5 hastada $(\% 7,46)$, akut nekroz olmaksızın, esas olarak pankreasta fokal genişleme veya pankreas kanalının genişlemesi olmak üzere pankreasta değişiklikler olduğunu bildirmiştir. Ayrıca bu çalışmada; pankreas hasarı olan 13 hastadan üçünde, ilk başvuru sırasında artmış amilaz ve lipaz değerleri mevcuttu. Buna ek olarak, iki hastada nonsteroid antiinflamatuar ilaç kullanımı öyküsü ve dört hasta hastanede kalış sırasında glukokortikoidlerle tedavi edilmiş olduğunda bu hastalarda ilaca bağlı pankreatit ile olabileceği bildirilmiştir. Pankreas hasarı olan beş hasta exitus olduğu ve 8 hastanın taburcu edildiği bildirilmiştir. Bu çalışma; COVID-19 hastalarının nekrotizan pankreatit belirtileri göstermese de, pankreas hasarının sonuçları potansiyel olarak ciddi olabileceğine (örneğin sistemik enflamasyonu şiddetlendirmek, akut solunum sıkıntısı sendromunun oluşumunu hızlandırmak ve hatta ciddi bir etkiye sahip olabilecek kronik pankreatite dönüşmek gibi) dikkat çekmiştir ${ }^{12}$.

Suchman ve ark.39 çocuk hastalardaki COVID-19 ilişkili pankreatiti irdeledikleri çalışmalarında; 8159 yatan hastanın 112'sinin (\% 1,37) COVID-19 tanısı aldığını, on üçüne pankreatit $(\%$ o,16) (13/8159) tanısı konduğunu bildirmiştir. Pankreatit ile başvuran on üç hastadan ikisinin (\% 1,8) COVID-19 pozitif olduğunu bildirmiştir. Bu çalışma, pankreatitin COVID-19'lu pediatrik hastalarda ortaya çıkabileceğini ve COVID19 popülasyonunda daha yaygın olabileceğini göstermektedir.

Literatürde COVID-19 pankreas tutulumu ile karşı görüşler de mevcuttur. Örneğin, deMadaria ve ark..$^{40}$ ise; Wang ve ark. ${ }^{10}$ makalesini eleştirmiş olup, pankreatit olarak sınıflandırılan hastalarda daha yüksek ishal insidansı ve daha yüksek kreatinin 
seviyelerine bağlı olarak pankreatik enzimlerin artmış olabileceğini belirtmiş, bu durumun doğrudan COVID-19 pankreas tutulumuna bağlı olmayabileceğini vurgulamıştır.

Önemli pankreas hasarı olmadan, şiddetli hastalık durumunda pankreasta "pankreatit benzeri klinik sendrom" olarak ikincil enzim anormallikleri saptayabilmektedir. Takiplerde iatrojenik olarak da ilaçlara sekonder enzim yükseklikleri olarak karşımıza çlkabilir. Klinik olarak genellikle şiddetli bir tablo göstermezler. Tedavileri takiplerde semptomatik tedavi olarak önerilmektedir ${ }^{12,41}$.

Akut pankreatitli hastanın aynı dönem SARS-COV-2 enfeksiyonu geçirmesi tedavi protokolünü değiştirmemektedir. Karın ağrısı geçene ve genel durumu düzelene kadar hastanın oral gıda alımı kesilir. Ancak enteral beslenme yapılabilir (nazogastrik veya nazojejunal tüpten infüzyon). Enteral beslenme, parenteral beslenmeden daha etkili olarak değerlendirilebilir. Yoğun aktif (agresif) sıvı tedavisi en önemli tedavi basamağıdır. Ağrı kesici olarak morfin dışındaki narkotik analjezikler verilebilir. Hastanın ciddi kusması yoksa nazogastrik sonda takılmaz. Enfekte pankreatik nekroz ve kolanjitte antimikrobiyal tedavi verilmelidir ${ }^{42}$.

Ayrıca son günlerde yayınlanan bir makalede COVID-19'da pankreas tutulumunda Tocilizumab (TCZ) ile tedavisi için yeni bir yöntem olabileceği bildirilmiştir ${ }^{42}$. Ancak şu anda bilimsel veriler sınırlıdır. Tocilizumab (TCZ), IL-6'nın reseptörüne (IL-6R) bağlanmasını rekabetçi bir şekilde inhibe eden bir monoklonal antikordur. Bu mekanizma, B ve T hücre aktivasyonundan sorumlu inflamatuar aracllara reseptör kompleks sinyal iletimini bloke eder ve sitokin firtınasını inhibe eder. Şiddetli COVID19 pnömonisi olan hastalarda mortaliteyi azaltmak için kullanılabilir43,44.

Zielecki ve ark. ${ }^{45} 38$ yaşında hepatosteatoz, hepatosplenomegali ve alkol bağımlılığı olan şiddetli COVID-19 pnömonisine eşlik eden, ödemli orta derecede AP tablosu olan tocilizumab ile etkili bir şekilde tedavi edilen bir hastayı bildirmiştir. Bu hasta; hastaneye kabulünde, tipik COVID-19 belirtisi olmaksızın akut pankreatit belirti ve semptomları ile başvurmuş ve birkaç gün sonra bir toraks bilgisayarlı tomografisi tipik COVID-19 bulgular göstermiştir. 2016 ve 2017 'de yapılan araştırmalar, tosilizumabın sıçan modellerinde deneysel şiddetli akut pankreatit ve akut akciğer hasarında önemli ölçüde 
etkili olabileceğini göstermiştir46,47. ABD Gıda ve İlaç Birliği (FDA) onaylı faz III, tocilizumab üzerinde randomize kontrollü çalışmalar devam etmektedir ${ }^{48}$.

Ancak bugüne kadar akut pankreatit tedavisinde TCZ'ı değerlendiren hiçbir insan çalışması yapılmamıştır. Akut pankreatit ve COVID-19 pnömonisi olan hastalarda tosilizumabın etkinliğini belirlemek zordur. İnsanlar hakkındaki veriler hala sınırlıdır ve COVID-19 pnömonisi ile ilişkili akut pankreatitin insidansı, seyri ve sonucu hakkında daha fazla bilgiye ihtiyacımız vardır43-44.

\section{Sonuç}

Sonuç olarak, şu ana kadar olan çalışmalarda saptandığı üzere COVID-19 çoğunlukla potansiyel hafif pankreas hasarlanmaları, klinik olarak komplikasyonsuz hafif -orta pankreatit bulguları ile karşımıza çıkmıştır. COVID-19 pnömonisi ile takip edilen her hastada doğrudan viral tutulumla ilişkili olabilir. Daha fazla araştırma ve daha büyük serilerde çalışmalar gerekmektedir. COVID-19 hastalarında pankreas enzimlerindeki artış giderek daha fazla tanınmaktadır, ancak bu popülasyonda akut pankreatitin gerçek prevalansı hakkında çok az şey bilinmektedir. Erişkinlerde olduğu gibi, COVID-19'lu çocuklarda pankreatitin ilişkisi veya prevalansı hakkında da sınırlı veri mevcuttur. Son çalışmalar ağırlıklı olarak enfeksiyonu doğrulanmış hastaların epidemiyolojik ve klinik özellikleri üzerine yapılmakta iken, SARS-CoV-2 enfeksiyonunun neden olduğu pankreas hasarı ile ilişkili gerek çocuklarda gerek erişkinlerde hem tedavi hem de patofizyoloji açısından daha çok araştırma yapılması gerekmektedir.

Çalışma daha önce herhangi bir kongre veya sempozyumda sunulmamıştır.

Yazarlar arasında çıkar çatışması veya finansal destek yoktur.

\section{KAYNAKLAR}

1. Kutlu O, Bilgiç Y, Bahri E, Atayan Y, Çağın YF. Alkolik olmayan yağlı karaciğer hastalığı rekürren akut pankreatit için bir risk faktörü müdür? Fırat Tıp Derg. 2020;25(3):135-139.

2. Mazrouei SSA, Saeed GA, Al Helali AA. COVID-19-associated acute pancreatitis: a rare cause of acute abdomen. Radiol Case Rep. 2020;15(9):1601-1603. doi: 10.1016/j.radcr.2020.06.019. 
3. Kottanattu L, Lava SAG, Helbling R, Simonetti GD, Bianchetti MG, Milani GP. Pancreatitis and cholecystitis in primary acute symptomatic Epstein-Barr virus infection - systematic review of the literature. J Clin Virol. 2016;82:51-55. doi: 10.1016/j.jcv.2016.06.017.

4. Agzarian AE. Agzarian AY. Influenza A as a cause of acute pancreatitis: a case report. Proceedings of UCLA Healthcare. 2016;20:1-2.

5. Sullivan SJ, Jacobson RM, Dowdle WR, Poland GA. 2009 H1N1 influenza. Mayo Clin Proc. 2010;85(1):64-76. doi: 10.4065/mcp.2009.0588.

6. https://covid19.who.int/who -Corona virüs disease (COVID-19) dashboard. Erişim tarihi 25 Ocak 2021.

7. Li LQ, Huang T, Wang YQ, et al. COVID-19 patients' clinical characteristics, discharge rate, and fatality rate of meta-analysis. J Med Virol. 2020;92(6):577583. doi: 10.1002/jmv.25757.

8. Holshue ML, DeBolt C, Lindquist S, et al. Washington State 2019-nCoV Case Investigation Team. First Case of 2019 Novel Coronavirus in the United States. N Engl J Med. 2020;382(10):929-936. doi: 10.1056/NEJMoa2001191.

9. Yang JK, Lin SS, Ji XJ, Guo LM. Binding of SARS coronavirus to its receptor damages islets and causes acute diabetes. Acta Diabetol. 2010;47(3):193-9. doi: 10.1007/s00592-009-0109-4.

10. Wang F, Wang H, Fan J, Zhang Y, Wang H, Zhao Q. Pancreatic injury patterns in patients with coronavirus disease 19 pneumonia. Gastroenterology. 2020;159(1):367-370. doi: 10.1053/j.gastro.2020.03.055

11. McNabb-Baltar J, Jin DX, Grover AS, et al. Lipase Elevation in Patients with COVID-19. Am J Gastroenterol. 2020;115(8):1286-1288. doi:10.14309/ajg.0000000000000732.

12. Liu F, Long X, Zhang B, Zhang W, Chen X, Zhang Z. ACE2 expression in pancreas may cause pancreatic damage after SARS-CoV-2 infection. Clin Gastroenterol Hepatol. 2020;18(9):2128-2130.e2. doi: 10.1016/j.cgh.2020.04.040 
13. Banks PA, Bollen TL, Dervenis C, et al. Acute Pancreatitis Classification Working Group. Classification of acute pancreatitis--2012: revision of the Atlanta classification and definitions by international consensus. Gut. 2013;62(1):102-11. doi: 10.1136/gutjnl-2012-302779.

14. Hadi A, Werge M, Kristiansen KT, et al. Coronavirus Disease-19 (COVID-19) associated with severe acute pancreatitis: case report on three family members. Pancreatology. 2020;20(4):665-667. doi: 10.1016/j.pan.2020.04.021.

15. İnkaya AÇ, Taş Z, Akova M. COVID-19'un güncel tedavisi. Yalçın Ş, Özet A, editörler. Kanser ve COVID-19 Pandemisi. 1. Baskı. Ankara: Türkiye Klinikleri; 2020. p.27-37.

16. Huang C, Wang Y, Li X, et al. Clinical features of patients infected with 2019 novel coronavirus in Wuhan, China. Lancet. 2020;395(10223):497-506. doi: 10.1016/So140-6736(20)30183-5.

17. Wong EC, Butch AW, Rosenblum JL. The clinical chemistry laboratory and acute pancreatitis. Clinical chemistry. 1993;39:234-43.

18. https://www.uptodate.com/contents/clinical-manifestations-and-diagnosis-ofacute-pancreatitis. Erişim tarihi 11 Ekim 2020.

19. Biberoğlu S, Koyuncu M, Öztürk D, et al. Role of computed tomography severity index in acute diagnosis and follow-up of acute pancreatitis. $J$ Clin Anal Med. 2017;8(2):106-110.

20. Docherty AB, Harrison EM, Green CA, et al. Features of 20133 UK patients in hospital with COVID-19 using the ISARIC WHO Clinical Characterisation Protocol: prospective observational cohort study. BMJ. 2020;369:m1985.

21. Zhang H, Kang Z, Gong H, et al. Digestive system is a potential route of COVID19: an analysis of single-cell coexpression pattern of key proteins in viral entry process. Gut. 2020;69:1010-8.

22. Ullah AZDM, Sivapalan L, Chelala C, Kocher HM. COVID-19 in patients with hepatobiliary and pancreatic diseases in East London: a single-centre cohort study. medRxiv. 2020.09.07.20189621; doi: https://doi.org/10.1101/2020.09.07.20189621 
23. Del Hoyo J, López-Muñoz P, Fernández-de la Varga M, et al. Hepatobiliary and Pancreatic: A fatal case of extensive splanchnic vein thrombosis in a patient with COVID-19. J Gastroenterol Hepatol. 2020;10.1111/jgh.15174. doi: 10.1111/jgh.15174.

24. Singla V, Arora A. Hepatobiliary and pancreatic manifestations of coronavirus disease 2019. Journal of Digestive Endoscopy . 2020;11(1):21-3. doi: 10.1055/s0040-1712079.

25. Gubatan J, Levitte S, Patel A, et al. Prevalence, risk factors and clinical outcomes of COVID-19 in patients with a history of pancreatitis in Northern California. Gut. 2021;70(2):440-441. doi: 10.1136/gutjnl-2020-321772.

26. Barlass U, Wiliams B, Dhana K, et al. Marked elevation of lipase in COVID-19 Disease: a cohort study. Clin Transl Gastroenterol. 2020;11(7):eoo215. doi: 10.14309/ctg.0000000000000215.

27. Ding Y, He L, Zhang Q, et al. Organ distribution of severe acute respiratory syndrome (SARS) associated coronavirus (SARS-CoV) in SARS patients: implications for pathogenesis and virus transmission pathways. J Pathol. 2004;203(2):622-30. doi: 10.1002/path.1560.

28. Hussain A, Bhowmik B, do Vale Moreira NC. COVID-19 and diabetes: Knowledge in progress. Diabetes Res Clin Pract. 2020;162:108142. doi: 10.1016/j.diabres.2020.108142.

29. Qian DH, Zhu GJ, Wu LZ, Hua GX. Isolation and characterization of a coronavirus from pigeons with pancreatitis. Am $J$ Vet Res. 2006;67(9):1575-9. doi: 10.246o/ajvr.67.9.1575.

30. Wills SE, Beaufrère HH, Brisson BA, Fraser RS, Smith DA. Pancreatitis and systemic coronavirus infection in a Ferret (Mustela putorius furo). Comp Med. 2018;68(3):208-211. doi: 10.30802/AALAS-CM-17-000109.

31. Aloysius MM, Thatti A, Gupta A, Sharma N, Bansal P, Goyal H. COVID-19 presenting as acutepancreatitis. Pancreatology. 2020;20(5):1026-1027. doi: 10.1016/j.pan.2020.05.003. 
32. Cheung S, Delgado Fuentes A, Fetterman AD. Recurrent acute pancreatitis in a patient with COVID-19 Infection. Am J Case Rep. 2020;21:e927076. doi: 10.12659/AJCR.927076.

33. Lakshmanan S, Malik A. Acute pancreatitis in mild COVID-19 infection. Cureus. 2020;12(8):e9886. doi: 10.7759/cureus.9886.

34. Nikhil Kumar Patnaik R, Gogia A, Kakar A. Acute pancreatic injury induced by COVID-19. IDCases. 2020;10:e00959. doi: 10.1016/j.idcr.2020.e00959.

35. Meireles PA, Bessa F, Gaspar P, et al. Acalculous acute pancreatitis in a COVID19 patient. Eur J Case Rep Intern Med. 2020;7(6):001710. doi: 10.12890/2020_001710.

36. Miao Y, Lidove O, Mauhin W. First case of acute pancreatitis related to SARSCoV-2 infection. Br J Surg. 2020;107(8):e270. doi: 10.1002/bjs.11741

37. Mukherjee R, Smith A, Sutton R. Covid-19-related pancreatic injury. Br J Surg. 2020;10.1002/bjs.11645 [Epub ahead of print]

38. Szatmary P, Arora A, Thomas Raraty MG, Joseph Dunne DF, Baron RD, Halloran CM. Emerging Phenotype of Severe Acute Respiratory SyndromeCoronavirus 2-associated Pancreatitis. Gastroenterology. 2020;So0165085(20)34741-7. doi:10.1053/j.gastro.2020.05.069.

39. Suchman K, Raphael KL, Liu Y, Wee D, Trindade AJ. Northwell COVID-19 Research Consortium. Acute pancreatitis in children hospitalized with COVID19. Pancreatology. 2021;21(1):31-33. doi: 10.1016/j.pan.2020.12.005.

40. De-Madaria E, Siau K, Cárdenas-Jaén K. Increased amylase and lipase in patients with COVID-19 pneumonia: don't blame the pancreas just yet! Gastroenterology. 2020;So016-5085(20)30561-8. doi:10.1053/j.gastro.2020.04.044.

41. Medpage Today. https://www.medpagetoday.com/infectiousdisease/covid19/88328. Erişim tarihi 10 Ekim 2020. 
42. Türk Cerrahi. Akut Pankreatit Tanısı.

https://www.turkcerrahi.com/makaleler/pankreas/akut-pankreatit/pankreatittanisi/. Erişim tarihi 10 Ekim 2020.

43. Zhang C, Wu Z, Li JW, Zhao H, Wang GQ. Cytokine release syndrome in severe COVID-19: interleukin-6 receptor antagonist tocilizumab may be the key to reduce mortality. Int J Antimicrob Agents. 2020;55(5):105954. doi: 10.1016/j.ijantimicag.2020.105954.

44. Guaraldi G, Meschiari M, Cozzi-Lepri A, et al. Tocilizumab in patients with severe COVID-19: a retrospective cohort study. Lancet Rheumatol. 2020;2(8):e474-e484. doi: 10.1016/S2665-9913(20)30173-9.

45. Zielecki P, Kaniewska M, Furmanek M, Bulski T, Rydzewska G. Effective treatment of severe acute pancreatitis and COVID-19 pneumonia with tocilizumab. Prz Gastroenterol. 2020;15(3):267-272. doi: 10.5114/pg.2020.99042.

46. Chen KL, Lv ZY, Yang HW, et al. Effects of tocilizumab on experimental severe acute pancreatitis and associated acute lung injury. Crit Care Med. 2016;44(8):e664-77. doi: 10.1097/CCM.ooooooooooo01639.

47. Hançerli Y, Kaplan M, Tanoğlu A, Yeşilbaş S, Küçükodacı Z, Yıldırım M. Efficacy of tocilizumab treatment in cerulein-induced experimental acute pancreatitis model in rats. Turk $J$ Gastroenterol. 2017;28(6):485-491. doi: 10.5152/tjg.2017.16738.

48. Clinical Trials. A Study to Evaluate the Safety and Efficacy of Tocilizumab in Patients With Severe COVID-19 Pneumoni (COVACTA). https://clinicaltrials.gov/ct2/show/NCT04320615. Erişim tarihi 5 Ekim 2020. 